\title{
Impact of Analogical Images on Solving Scientific and Environmental Problems Creatively
}

\author{
Mohammed Talib Alkiyumi \\ Ministry of Education, Muscat, Sultanate of Oman
}

\begin{abstract}
This study investigates the impact of analogical images on students' creative abilities of novelty and offeasibility, through solving scientific and environmental problems. There are eight problems: fours cientific and four environmental derived from content-text of science and social studies curricula which were provided to the students. The experiment was implemented over 4 weeks. Analogical images were provided to the experimental groups, whereas control groups were asked to solve the problems abstractly. The experiment was based on the activation of the cerebellumby analogical images to improve creativeabilities. A $2 \times 2$ factorial design was used. A total of 112 sixth-grade students (45 males \& 67 females) from two government schools in Muscat governorate participated in this study. The sample was classified into four classes: two experimental and two control. The findings show that: (a) the experimental group performed better on problem-solving than the control group did; (b) design not gender has the most effect on alinear combination of novelty and feasibility; and (c) gender and design have the most effect on alinear combination of scientific and environmental problems.
\end{abstract}

Keywords: analogy, images, problem-solving, creativity

\section{Introduction}

Creativity researchers face a mysterious question of how the mind processes creative thinking. The newest approach focuses on studying this potential physically by using an euro imaging scan, which is a feasible approach of studying creativity that provides valid information on processing this potential. The neuro-psychological data provided by neuroimaging techniques such as PET (positron emission tomography), fMRI (functional magnetic resonance imaging), and EEG (electro encephalo graphy) present substantial evidence of how creativity could be activated. Experimental evidence shows that brains of creative and intelligent people differ in the density of synaptic connections (Duch, 2007). Therefore, as much as creative complexity, a highly coordinated interplay of different neural networks is needed (Fink, Benedek, Grabner, Stoudt, \& Neubauer, 2007). The question of how creativity can be activated is still unresolved although numerous techniques for activating creativity have been provided through various studies. Visualization is apractical method that studies (e.g., Kosslyn \& Ochsner, 1994; Ronald \& Gulyas, 1994; Sakai \& Miyashita, 1994) have shown to have an impact on imagery. Clearly, this empirical evidence support the views that individual differences in visual perception affect the richness of their imagery. Kosslyn (1994), and Miyashita (1995) report that visual imagery seems to evoke activity in the primary visual cortex. It is consistently seen that visual imagery is essential in stimulating thec reative mind, as shown in studies by Finke (1990), Gillian

Mohammed Talib Alkiyumi, Ph.D., Ministry of Education. 
(1988), and Shepard and Cooper (1982).

Vandervert, Schimpf, and Liu (2003, p. 1) provide a theory of how the continuously repetitive process of working memory that is learned as cognitive control models in the cerebellum results in creativity and innovation. They state that "the cerebellar control models consist of multiple-paired predictor (forward) models within MOSAIC (the Modular selection and identification for control) and HMOSAIC (hierarchical MOSAIC) cerebellar architecture that explore and test problem-solving requirements".

Vandervert et al.'s (2003) theory is consistent with Dietrich's (2004) model, which emphasizes that creativity requires avariety of classic front all obe-demanding cognitive abilities such as working memory, sustained attention, and cognitive flexibility. Additionally, Vandervert et al.'s (2003) theory is based on Mandler's continuous studies $(1977 ; 1978 ; 1984)$ on image schemas, which claim that ametaphor of the image schemas is a basic for imagery conceptualization through the thought process. In particular, this perspective is related to the theory because of providing the bottom-up meaning basis for the visuos patial sketch padina foundation allayer of HMOSAIC.

Moreover, Vandervert et al.'s (2003) theory also relies on the perspective of Einstein's creative work. Einstein stated how the central executive is guided by using signs and images that can be manipulated in the visuospatial sketchpad, while the conventional word comes as a secondary stage. Vandervert et al.'s (2003) theory emphasizes two concerns: First, the role played by analogy in solving problems; second, the complete absence of long-term memory in idea generation (Jalil, 2007). Furthermore, Vandervert et al.'s (2003) state that creative thought involves forecasts of actions that are forecast based on images and hypotheses. The images are consistent with the model of Vandervertetal which implies forecasting future outcomes of action. Moreover, these forecasts are based on images or hypotheses which provide generation of new ideas (Mumford \& Caughron, 2007).

\section{Visual Images}

According to Barry (1997), the term “image" implies two meanings: mental image (image on the brain) and exteriorized image. Arnheim (1969) and Gardner (1983\1993) emphasized through their creative thinking studies the salient role of images in thinking. This is because imagination, which is a basic element of generating new idea relies on the ability to read and build visual images. Visual imagery and visual stimulus may share some commoncortical processing areas. Neuro imaging studies report that at least some higher-order visual areas in the temporal and parietal lobes participate not only in visual perception, but also in visual imagery (D’Esposito et al., 1997; Kossyln \& Ochsner, 1994; Moscovitch, Wincour, \& Behrmann, 1997; Roland \& Gulyas, 1994; Sakai \& Miyashita, 1994). Consequently, studies by other researchers (Ishai \& Sagi, 1995; Kossyln \& Oschsner, 1994; Le Bihan, Turner, Zeffiro, Cuenod, Jezzard, \& Bonnerot, 1993; Menon, Ogawa, Tank, Ellermann, Merkele, \& Ugurbil, 1993; Miyashita, 1995) demonstrate that visual imagery evokes activity in the primary visual cortex, but some studies (Pylyshyn, 2002, 2003; Kosslyn \& Thompson, 2003) do not demonstrate that impact.

Kosslyn (2005, p. 334) provides a "theory of mentalimagery", which focuses on the dual role of the early visual cortex on perception and imagery. He states that visual perception occurs while a stimulus is being viewed, and it includes visual recognition and identification. On the other hand, "Visual mental imagery is a set of representations that give rise to the experience of viewing astimulus in the absence of appropriate sensoryinput".

A study by Choi and Kim (2007) shows that the interaction between internal organizations and spatial 
forms in the physical environment categories leads to differences in perceived creative potential. Light and color categories do not seem to contribute to these differences. Another study by Choi and Kim (2005) used visual images of interior design elements. Nakakoji, Yamamoto, and Ohira (1999) also used visual images, but to develop creative computer system design. Meanwhile, a study by McCoy and Evans (2002) used physical environment images that enhanced creativity. A study by Harland and Coren (2001) consistently, found that poor visual acuity and stereopsis may reduce creative task-solving because the effectiveness of imagery in achieving novel solutions is reduced when stored images are lacking in detail. A study by Smith, Susan, and Edward (1995) found a positive relationship between colorful and dynamic images on the other hand, and problem-solving on the other. Also, this study showed that creative students were better at describing images in more detail.

The integrative function of visual/spatial is connected with thinking and creativity (Marshall, 2007). This connection between creative thinking and visual $\backslash$ spatial thinking has been investigated by Gardner (1983) who argues in his theory of spatial intelligence about the power of visual images in enabling the mind to transform.

The experimental evidence demonstrates that visual images assist in providing the ability to recognize the connection between two situations and their solution methods, which is called analogy. Miller (2007, p. 48) provides a network thinking model which emphasizes the role of mental images and metaphor in creating novel ideas. He states, "The urge to solve a problem serves to 'hold' it in the unconscious where concepts from apparently disparate disciplines are combined by proper choice of mental image or metaphorto catalyze the nascent moment ofcreativity".

Using images for creative thought helps the brain to perceive, fantasize, transit, and experience hypnagogia. These cognitive states imply motoric connotations which interact with images as a problem to visuo image a solution. Visual imagery is important for inciting new circuits from the brain whenever it encounters an ill-defined problem. This state is called "insight" (Duch, 2007). Clearly, visual images enable students to read and think overa problem and divine the reasons behind it. This state makes them imagine the solutionby analogizing the problem with related phenomena. Einstein asserted the importance of visual imagery in his creative thinking, which Vandervert et al.'s (2003) note (Thomas, Place, \& Hillyard, 2008).

\section{Analogy}

The basic element of Vandervert et al.'s (2003) theory is extension of the analogy to create novel solutions to intellectual problems (Marshall, 2007). "Analogy, of course is more than association. Analogical thinking involves some more or less sustained comparison between the internal and structure of the two ideas concerned" (Boden, 1999, p. 354). Analogical reasoning is a method of solving problems creatively. Analogy enables the individual to transfer ideas across domains (Gomes, Seco, Pereira, Paiva, Carreiro, \& Ferreira, 2006). These creative acts created by the imagination, and such analogies could be considered as the result of a relation established in the mind through a process of selective emphasis (Bonnardel, 2000). Studies by Brown and Kane (1988), and Goswami (1991) found that children need hints from the source problem solution to solve the target problem. Siegler (2006), and Tuntoler and Resing (2007) insistthat children spont aneously use analogical images while solving problems.

Analogical images were a strategy used by Darwin while constructing his outstanding theory of evolution. He mapped the findings of natural pictures in the form of a tree. Perceiving and forming the relations between them is a cognitive model that has deep metaphorical roots (Marshall, 2007). Gardner (1983) insists on 
metaphorical thinking about visual images in spatial thinking. Moreover, West (1997), based on Gardner's and Arnheim's work, argues that visual thinking in the integrative mental modality enables us to grasp the big picture simultaneously and instantly.

Miller (1996-2001), when he developed the theory of construction on science examined the imaginative insight which evoked the most physics break throughs. "A truly new insight, however, often requires a conceptual leap that is not based on rationality alone. This leap occurs through metaphor and metaphorical images" (Marshall, 2007, p. 31). Most studies (e.g., Brown, 1989; Goswami, 1991) agree that children are more competentat generating analogous solutions to related problems than was previously believed (Tuntoler \& Resing, 2007).

Bonnardel (2000) uses design activities to test how analogical reasoning evokes creativity in graphic design. In his experiment, students dealt with specific problems to see whether the solutions referred to similar problems for which a solution already existed. He found that the designers who analogue the stated problem with solutions of related problems were significantly more spontaneous and creative in their solutions than the designers from the free group. A study by Antonietti (2000) showed that using analogies through a teaching process affected students' creative abilities significantly. Furthermore, a study By Novick and Holyoak (1991) showed the significant impact of analogy on solving mathematical problems. Gomes et al. (2006) conducted six experiments for choosing the most effective strategy for use through analogy. They used are trieval process to study thecor relation between analogical retrieval strategies and creative properties of generated diagrams in the soft ware design domain. A study by Keane (1996) found that adaptability played a crucial role in selecting mapping while using analogy to solve problems. In addition astudy by Tuntoler and Resing (2007) shows that students who had prior assistance in using analogies were significantly better at analogical problem-solving than others. The study proves the importance of using analogical reasoning in the learning process while solving problems. Researchers (e.g., Brown \& Kane, 1988; Brown, Kane, \& Echols, 1986; Chen, 1996; Chen \& Daehler, 1992) have used the analogy process to solve genuine problems faced in thereal world of students after learning the solutions of related problems.

\section{Purposes of the Study}

Broadening the cognitive approach of studying creativity focusing on mind activation involved two united activators: images and analogy (analogical images). The study is based on Vandervert et al.'s (2003) theory, which states that activation of the cerebellum positively affect creative abilities. Analogy and visual images are combined in this study to investigate whether they positively affect creative abilities according to the study's limitations. The first goal of the study is to investigate whether using analogical images has positive effect on creative abilities. The second goal is to investigate whether gender and type of manipulation have different effects on the creative abilities: novelty and feasibility. The third goal is to identify whether there are different effects from gender and manipulation on solving scientific and environmental problems. The study's findings will contribute to the scope of the cognitive approach and the consideration of the theory of Vandervert et al.'s (2003).

\section{Methods}

A $2 \times 2$ factorial design was used in this study due to two independent variables being included: gender (male \& female), and manipulation (experiment \& control) groups. The dependent variables are abilities of 
problem-solving: novelty, which refers to creating new ideas disregarding conventional or routine ideas; and feasibility, which refers to execution capabilities. Participants were 112 sixth-grade students from the Governorate of Muscat ( 45 male \& 67 female) divided into four classes: two male-female experimental groups, and two male-female control group classes. In the experimental group, the investigator used the analogical visuo images technique for encouraging students to generate creative solutions to a problem, while in the control group, a researcher asked the students to solve problem abstractly.

\section{Measures}

Analogical visual images. All the participants were asked to solve eight problems: four scientific problems and four environmental problems derived from content texts of science and social studies curricula. The experimental groups were provided with two visual images that represented the core of the problem. The first image was oriented towards expressing the problem, and enabled the students to read the problem and comprehend it (original image). The second image was an analogical image which expressed the analogical solved problem. The analogical images hinted to the students how problem had been solved, and, or enabled them to conceive the association between the two images. Responses were recorded concerning the assessment tool for solving problems, which was divided into two sub-abilities: novelty and feasibility. Scores ranked from 0 to 4 on eachability.

Environmental problems. (1) How can we retain the flowing water of the valleys instead of draining it into the sea?

Analogical images representing the methods of some desert trees that adapt to the lack of water (see Figure 1).

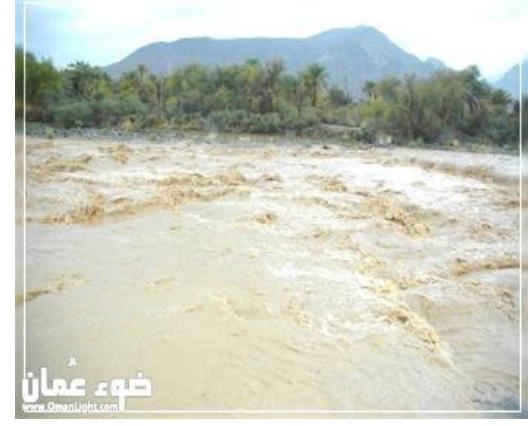

(a) Original image

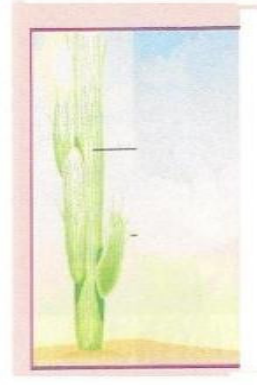

(b) Analogical image

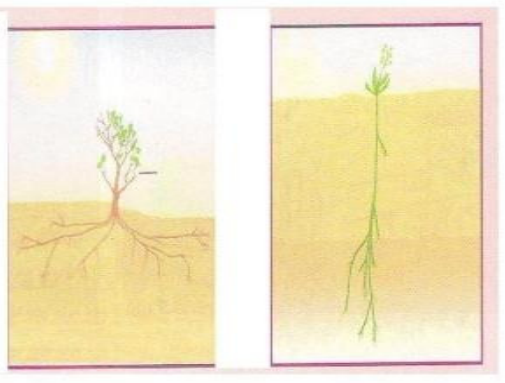

Figure 1. Analogical images of flowing water of the valleys and some desert trees that adopt to the lack of water.

(2) How can we solve the overgrazing problem? Analogical image of substituting players during a football match (see Figure 2).

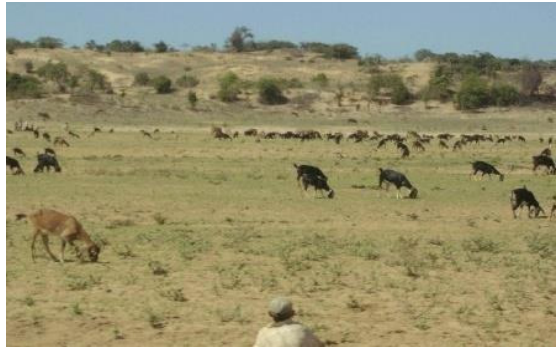

(a) Original image

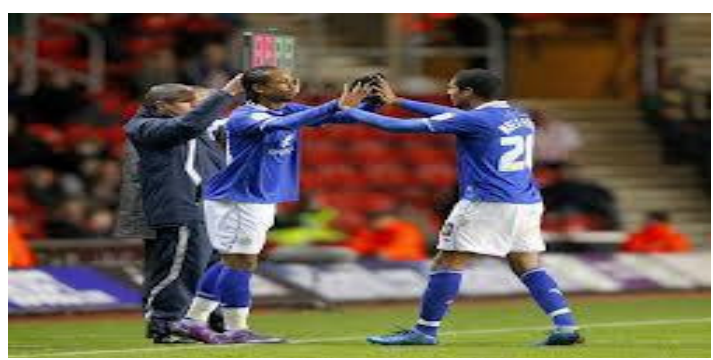

(b) Analogical image

Figure 2. Analogical images of overgazing problem and substituting players duringa football match. 
(3) What are your inferences when comparing a camel with a giraffe and a donkey with a zebra when you know that the area has valleys and trees? Analogical image of car models (see Figure 3 ).
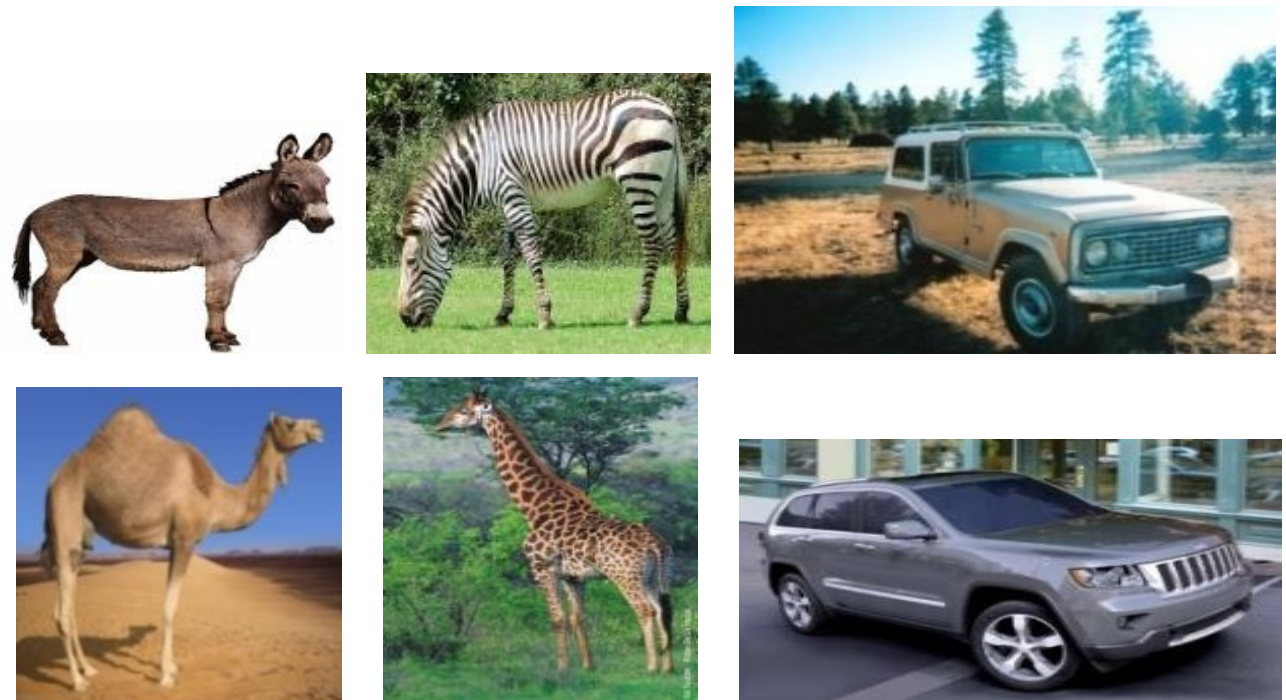

(a) Original image

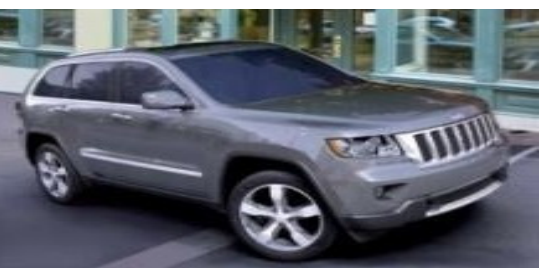

(b) Analogical image

Figure 3. Analogical images of animals in a different areas and different cars' models.

(4) How could we prevent the salination problem? Analogical image of some diets elements (see Figure 4).

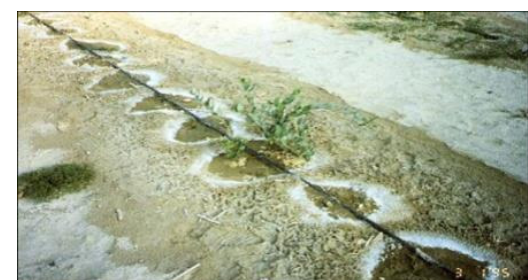

(a) Original image

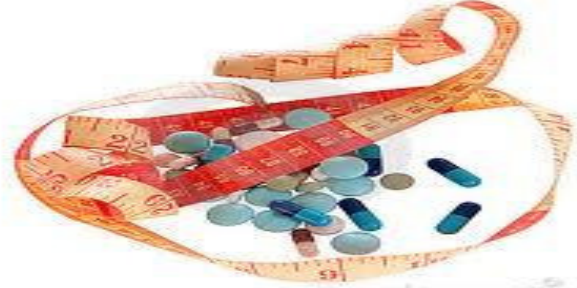

(b) Analogical image

Figure 4. Analogical images of salination problem and some diet elements.

Scientific problems. (1) How could we get rid of industrial smoke? Analogical image of water draining (see Figure 5).

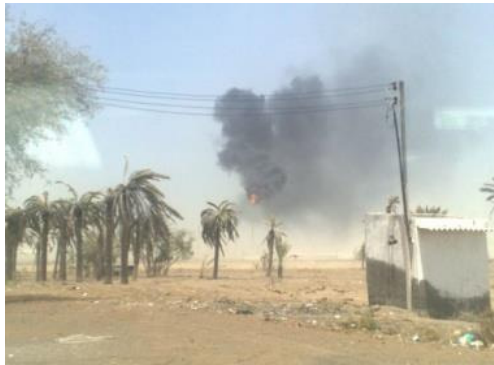

(a) Original image

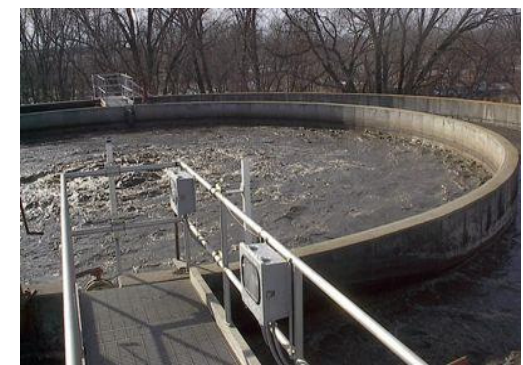

(b) Analogical image

Figure 5. Analogical images of industrial smoke problem and water draining.

(2) What is the alternative to wires in buildings and houses? Analogical image of mobile phones (see Figure 6). 


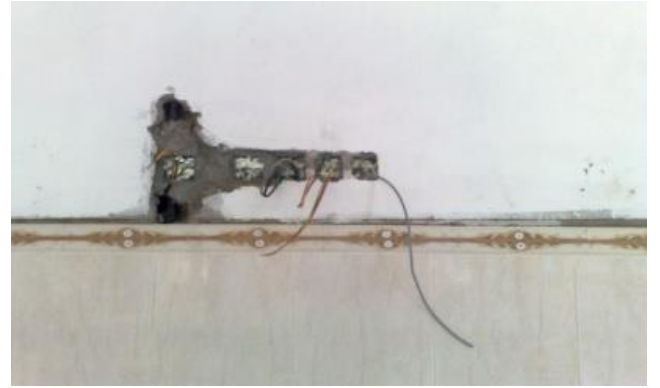

(a) Original image

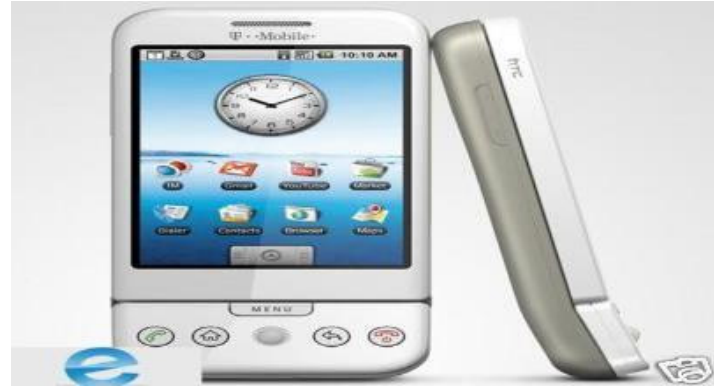

(b) Analogical image

Figure 6. Analogical images of using wires in buildings and mobile phones.

(3) Design a model of a plain based on the drag on fly's movement. Analogical image of drag on fly (see Figure 7).

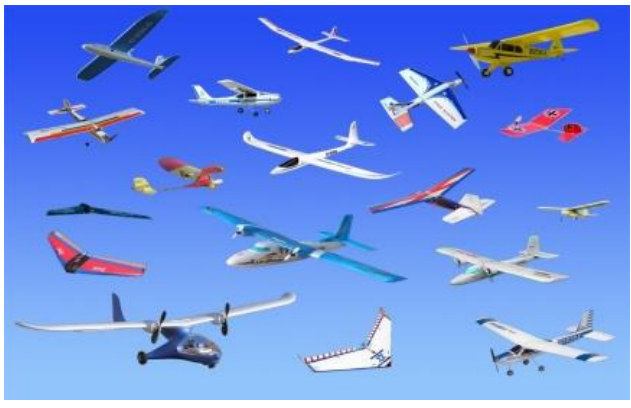

(a) Original image

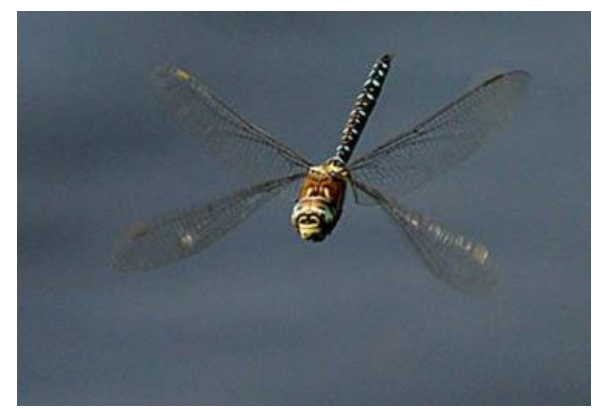

(b) Analogical image

Figure 7. Analogical images of plains' models and dragon fly.

(4) Based on the spider's web, design a model to solve the problem of traffic congestion in Muscat (see Figure 8).

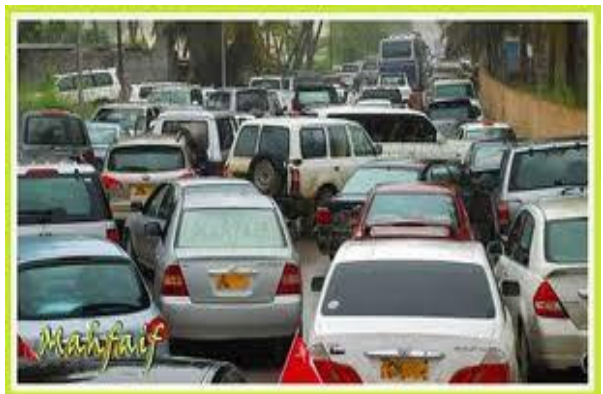

(a) Original image

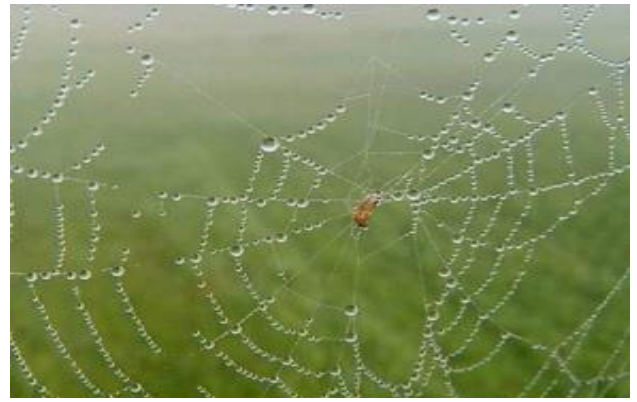

(b) Analogical image

Figure 8. Analogical images of congestion in Muscat and spider's web.

The validity of this assessment tool was tested by eight teachers who teach Science and Social Studies. The inter-judge reliability provided a satisfactory consistency of three raters.

\section{Procedures}

Multi-stage cluster sampling was used to identify the study's sample. Two schools from Muscat governorate were assigned (Shojabin Assad and Aseelabint Qais). Using the students' achievements and consultations with teachers, two equal classes were selected in both schools. 


\section{Experimental Manipulation}

This study was implemented over four weeks. Two problems, one environmental and one scientific were presented in one period for each group, with four periods assigned for the experimental group, and four periods assigned for the control group in each school. The students were asked to write their new solutions immediately on ananswer sheet. In the experimental groups, students used analogical visuo images to generate solutions, as opposed to the control groups, who thought abstractly and used their imagination to generate solutions.

\section{Main Questions}

Q1: Are there any significant differences between experimental and control groups in problem-solving achievement?

Q2: Are there any significant differences between novelty and feasibility with regard to gender and way of manipulation?

Q3: Do students who differ in gender and way of manipulation differ on alinear combination of achievement on scientific and environmental problems?

A $T$-test was used to answer Q1, Q2, and Q3 were answered by using two-way MANOVA (multivariate analysisof variance).

\section{Findings}

A $T$-test for independent samples was used to check whether there were significant differences between experimental and control groups on problem-solving achievement. Table 1 shows that the control group significantly differed from the experimental group $(\leq 0.005)$.

Table 1

T-test for Experimental and Control Group

\begin{tabular}{|c|c|c|c|c|c|c|c|c|}
\hline & & \multicolumn{5}{|c|}{$T$-test for equality of means } & \multirow{2}{*}{\multicolumn{2}{|c|}{$\begin{array}{l}95 \% \text { confidence interval of the } \\
\text { difference }\end{array}$}} \\
\hline & & & & & & & & \\
\hline & & $t$ & $d f$ & $\begin{array}{l}\text { Sig. } \\
\text { (2-tailed) }\end{array}$ & $\begin{array}{l}\text { Mean } \\
\text { difference }\end{array}$ & $\begin{array}{l}\text { Std. } \\
\text { error difference }\end{array}$ & Lower & Upper \\
\hline \multirow{2}{*}{ Problems } & $\begin{array}{l}\text { Equal } \\
\text { variances assumed }\end{array}$ & 2.846 & 108 & 0.005 & 3.85180 & 1.35364 & 1.16865 & 6.53495 \\
\hline & $\begin{array}{l}\text { Equal variances } \\
\text { not assumed }\end{array}$ & 2.846 & 107.904 & 0.005 & 3.85180 & 1.35364 & 1.16863 & 6.53498 \\
\hline
\end{tabular}

Table 2 shows that the mean of the experimental group was (27.52), which is significantly higher than that of control group (23.6). The effect size $(d)$ for this result is 0.55 , which is medium to large-size.

Table 2

Statistics of Experimental and Control Groups

\begin{tabular}{llllll}
\hline & Design & $N$ & Mean & Std. deviation & Std. error Mean \\
\hline \multirow{2}{*}{ Problems } & Experiment & 55 & 27.5275 & 6.99183 & 0.94278 \\
& Control & 55 & 23.6757 & 7.20368 & 0.97134 \\
\hline
\end{tabular}

Multi variate analysis of variance (2-way MANOVA) was used to test whether there were significant differences between novelty and feasibility with regard to gender and way of manipulation. Table 3 shows that Wilks' Lambda indicates that design has a significant main effecton alinear combination of novelty and 
feasibility $(F(5.568), d f=105, P=0.005)$. On the other hand, Wilks' Lambda indicates that the main effect of gender on novelty and feasibility was not significant $(F(3.228), d f=105, P=0.055)$. The interaction between gender and experiment was not significant $(F(1.207), d f=105, P=0.303)$.

Table 3

Multivariate Tests of Novelty and Feasibility With Regard to Gender and Way of Manipulation

\begin{tabular}{|c|c|c|c|c|c|c|c|}
\hline Effect & & Value & $F$ & Hypothesis $d f$ & Error $d f$ & Sig. & Partial eta squared \\
\hline Gender & Wilks' Lambda & 0.942 & $3.228^{\mathrm{a}}$ & 2.000 & 105.000 & 0.055 & 0.058 \\
\hline Design & Wilks' Lambda & 0.904 & $5.568^{\mathrm{a}}$ & 2.000 & 105.000 & 0.005 & 0.096 \\
\hline Gender*design & Wilks' Lambda & 0.978 & $1.207^{\mathrm{a}}$ & 2.000 & 105.000 & 0.303 & 0.022 \\
\hline
\end{tabular}

Table 4 shows that tests of between-subject effects indicate that the means and standard deviations of the group design have a major effect on novelty $(P=0.001)$ with effect size (eta $=30)$, and on feasibility $(P=$ 0.012 , eta $=0.24)$. The main effect of gender on feasibility was significant $(P=0.013$, with eta $=23.8)$, but was not significant on novelty $\left(P=0.076\right.$, eta $=0.17$, multivariate $\left.\eta^{2}=0.96\right)$. This means that the linear combination of novelty and feasibility differed regarding the control and experimental groups. Multivariate $\eta^{2}=$ 0.58 shows that the linear combination of novelty and feasibility did not differ with regard to male and female.

Table 4

Tests of Between-Subjects Effects ofNovelty and Originality Based on Gender and Design

\begin{tabular}{llllllll}
\hline \multirow{2}{*}{ Gender } & $\begin{array}{l}\text { Dependent } \\
\text { variable }\end{array}$ & $\begin{array}{l}\text { Type III sum of } \\
\text { squares }\end{array}$ & $d f$ & $\begin{array}{l}\text { Mean } \\
\text { square }\end{array}$ & $F$ & Sig. & $\begin{array}{l}\text { Partial eta } \\
\text { squared }\end{array}$ \\
\hline \multirow{2}{*}{ Design } & Total novelty & 34.148 & 1 & 34.148 & 3.204 & 0.076 & 0.029 \\
& Total feasibility & 108.250 & 1 & 108.250 & 6.452 & 0.013 & 0.057 \\
\hline & Total novelty & 119.790 & 1 & 119.790 & 11.241 & 0.001 & 0.096 \\
& Total feasibility & 110.741 & 1 & 110.741 & 6.600 & 0.012 & 0.059 \\
\hline
\end{tabular}

Multi variate analysis of variance (2-way MANOVA) was used to test whether the students who differ in gender and way of manipulation differ on alinear combination of achievement on scientific and environmental problems. Table 5 shows that Wilks' Lambda indicates that gender has significant main effects on alinear combination of scientific and environmental problem $\left(F(3.583), d f=105, P=031\right.$, multivariate $\left.\eta^{2}=0.064\right)$. Moreover, Wilks' Lambda indicates that the main effect of design on scientific and environmental problems was significant $\left(F(6.756), d f=105, P=0.002\right.$, multivariate $\left.\eta^{2}=0.114\right)$.

Table 5

Multivariate Tests of Achievement in Solving Scientific and Environmental Problems With Regard to Genderand Method of Manipulation

\begin{tabular}{llllllll}
\hline Effect & & Value & $F$ & Hypothesis $d f$ & Error $d f$ & Sig. eta & Squared \\
\hline Gender & Wilks' Lambda & 0.936 & $3.583^{\mathrm{a}}$ & 2.000 & 105.000 & 0.031 & 0.064 \\
Design & Wilks' Lambda & 0.886 & $6.736^{\mathrm{a}}$ & 2.000 & 105.000 & 0.002 & 0.114 \\
\hline
\end{tabular}

Table 6 shows the test of between-subject effects indicating the means and standard deviation of the groups. Gender has a significant main effect on environment $(P=0.009)$, with effect size (eta $=0.25)$, but not on scientific problems $(P=0.213)$ with small effect size $($ eta $=0.12)$. The main effect of design on scientific problems was significant $(P=0.000)$ with effect size $($ eta $=0.33)$, but not on environmental problems $(P=$ 
$0.152)$ with small effect size $(e t a=0.13)$.

Table 6

Tests of Between-Subject Effects of Achievement on Scientific and Environmental Problems Based on Gender and Design

\begin{tabular}{llllllll}
\hline & Dependent variable & Type III sum of squares & $d f$ & $\begin{array}{l}\text { Mean } \\
\text { square }\end{array}$ & $F$ & Sig. & Partial eta squared \\
\hline \multirow{2}{*}{ Gender } & Total scientific & 28.045 & 1 & 28.045 & 1.572 & 0.213 & 0.015 \\
& Total environment & 119.950 & 1 & 119.950 & 7.184 & 0.009 & 0.063 \\
\hline \multirow{2}{*}{ Design } & Total scientific & 242.619 & 1 & 242.619 & 13.599 & 0.000 & 0.114 \\
& Total environment & 34.715 & 1 & 34.715 & 2.079 & 0.152 & 0.019 \\
\hline
\end{tabular}

\section{Discussion of Findings}

The most important finding of this study was the effect of analogical images on activating the mind to solve problems creatively. The images that were provided to the experimental groups made it easier for the students' minds to associate between two situations, and a connection happened between visual (images) and spatial (perception). Trying to proceed and get relationship between the methods of solving the two situations gives them a great opportunity for rich imagination (visualimagery). Kosslyn (1994) and Miyashita (1995) report that visual imagery seems to evoke activity in the primary visual cortex. The power of the analogy is in transforming the ideas between two situations which facilitate catalyzing anascent momentof creativity. Visual images have a power which makes the mind transform one situation into another (Gardner, 1983). Leaps of the mind occur through the metaphors that are presented to the students. Bonnardle (2000) insisted that analogy should be accompanied by an appropriate element that enables the creator to construct through creative process. Clearly combining analogy and visual images contributed significantly to the experimental group performing the leap from one structure to another and devising better creative solutions. In this context, the process of transforming the information of the images creates a new job for the mind which expands the imagery and deepens the thought process. Vandervert et al.'s (2003) theory states that the mind conceptualizes the imagination through the thought process, and this is the result of the metaphor of the image schemas. This perspective is related to the theory because it provides the bottom-up meaning basis for the visuos patial sketch padina foundational layer of HMOSAIC.

One possible reason for this finding is that visual areas in the temporal and parietal lobes participate in visual imagery (D’Esposito et al., 1997). The stimulus (images) activate visual perception (Kossyln, 2005). This finding is consistent with findings of studies by Choi and Kim (2005), and McCoy and Evans (2002). Moreover, the images reflected real problems, so that students appreciate them naturally, and feel the importance of solving them. Harland and Cornen (2001) found that acuity and stereops is visual images reduced creative problem-solving. Visual thinking, instead of abstract thought, provides a good opportunity to the mind to transfer ideas across domains. Therefore, this enables students to tackle the problems from different perspectives, and this helps to verify the solutions. The original image gives the students a clue that they use to solve the targeted problem. The importance of visual images and metaphors in activating the students' imagery and perception leads to these condfinding, that the experimental group was better than the control group in students' responses of novelty and originality. The most interesting finding is that the effect of gender on novelty and feasibility was not significant. The one possible of the result refers to the similar manipulation that was used among the groups, and to the same learning environment that provided to the 
both groups. Moreover, teachers were used same instructional strategies that may lack of aims towards enhancing creative abilities. Another possible explanation is that the problems that were provided to the students derived from the content of students' curricula which are the same for both girls and boys. Mostly, there are no differences between the learning environments of male and female schools. Incontrast, manipulation had significant effect on the experimental groups because the researcher evoked creative abilities by visual images that had an analogy which differed from solving the problems abstractly in the control groups.

\section{Limitations and Future Research}

There were limitations to this study that are worth noting. The data were collected from government schools. Consequently, the results may not be generalized to privates chools. Moreover, the subjects were in grade six (elementary chool). Therefore, results should not be generalized about other grades. Another potential limitation was the type of problems which were scientific and environmental problems. Consequently, the findings should not be assumed to be the same for other curricula. Recognizing of this study's limitations and its findings, there are still many possibilities for future research that may use other techniques and variables. Research that considers other problems such aslinguistic or mathematical problems are highly recognized. Moreover, future research may explore other creative abilities such as originality, fluency, and elaboration. The significant effect of analogical images should encourage researchers to compare the effect of analogy and visual images on creative abilities.

\section{References}

Arnheim, R. (1969). Visual thinking. Berkeley and Los Angeles: University of California Press.

Bafghi, S., \& Hossein, S. (1984). Effects of time press and imagery control on creativity in the production of verbal originality and creative analogy. Retrieved from ProQuest dissertations and theses database. (UMINo: 8428152)

Barry, A. (1997). Visual intelligence: Perception, image, and manipulation in visual communication. Albany State University of New York Press.

Boden, M. A. (1999). Computer models of creativity. In R. Sternberg (Ed.), Handbook of creativity (pp. 351-372). Cambridge: Cambridge University Press.

Bonnardel, N. (2000). Towards understanding and supporting creativity in design: Analogies in a constrained cognitive environment. Knowledge-Based Systems, 13, 505-513.

Brown, A. (1989). Analogical learning and transfer: What develops? In S. Vosnidou \& A. Ortony (Eds.), Similarity and analogical reasoning (pp. 369-412). New York: Cambrige University Press.

Brown, A., \& Kane, M. (1988). Preschool children an learn to transfer: Learning to learn and learning by example. Cognitive Psychology, 20, 493-523.

Brown, A., Kane, M., \& Echols, C. (1986). Young children's mental models determine analogical transfer across problems with a common goal structure. Cognitive Development, 1, 103-121.

Brown, J. (2007). On Vandervert et al. "Working Memory, Cerebellum, and Creativity". Creativity Research Journal, 19(1), 25-29.

Chen, Z. (1996). Children's analogical problem solving: Effects of superficial, structural, and procedural features. Journal of Experimental Child Psychology, 62, 410-431.

Chen, Z., \& Daehler, M. W. (1992). Intention and outcome: Key components of causal structure facilitating mapping in children's analogical transfer. Journal of Experimental Child Psychology, 53, 237-257.

Choi, J., \& Kim, C. (2005). Creativity and visual images of physical environment in a museum. The Korean Journal of Thinking \& Problem Solving, 17(1), 87-106.

Choi,J., \&Kim, C. (2007). Environmental effects on gene expression phenotype have regional biases in thehuman genome.Genetics, 175(4), 1607-1613. 
Daniel, F., \& Ruth, S. (1995). Images of creativity: The relationship of imagery, everyday cognition, and creative potential among high school students with exceptional abilities in the arts and sciences. Retrieved from ProQuest dissertations and theses database. (UMI No: 9526868)

D’Esposito, M., Detre, J. A., Aguirre, G. K., Stallcup, M., Alsop, D. C., Tippet, L. J., \& Farah, M. J. (1997). A functional MRI study of mental image generation. Neuropsychologia, 35,725-730.

Dietrich, A. (2004). The cognitive neuroscience of creativity. Psychonomic Bulletin \& Review, 11, 1011-1026.

Duch, W. (2007). Creativity and the brain. In Ai-Girl Tan (Ed.), A hand book of creativity for teachers (pp. 507-530). Singapore: World Scientific Publishing.

Finke, R. A. (1985). Theories relating mental imagery to perception. Psychological Bulletin, 98, 236.

Finke, R. A. (1990). Creativeimagery: Discoveries and inventions in visualization. Hillsdale, N. J.: Eribaum.

Fink, A., Benedek, M., Grabner, H., Staudt, B., \& Neubauer, C. (2007). Creativity meets neuroscience: Experimental tasks for the neuro scientific study of creative thinking. Methods, 42(2007), 68-76.

Gardner, H. (1983;1993). Frames of mind: The theory of multiple intelligences. New York: Basic Books.

Gillian, E. (1988). Thinking in visual images in the information age-The changing faces of the school. Gifted Education International, 5(2), 97-103.

Gomes, P., Seco, N., Pereira, C., Paiva, P., Carreiro, P., \& Ferreira, L. (2006). The importance of retrieval in creative design analogies. Knowledge-Based Systems, 19, 480-488.

Goswami, U. (1991). Analogical reasoning: What develops? A review of research and theory. Child Development, 62, 1-22.

Harland, R. E., \& Coren, S. (2001). Individual differences in divergent thinking as a function of variations in sensory status. Creativity Research Journal, 13(3/4), 385-391.

Ishai, A., \& Sagi, D. (1995). Common mechanisms of visual imageryandperception. Science, 268,1772-1774.

Jalil, P. A. (2007). Working memory, cerebellum, and creativity. Creativity Research Journal, 19(1), 39-45.

Keane, M. T. (1996). On adaptation in analogy: Tests of pragmatic importance and adaptability in analogical problem solving. The Quarterly Journal of Experimental Psychology, 49A(4), 1062-1085.

Koestler, A. (1964). The act of creation. New York: Penguin Books.

Kosslyn, S. M. (1994). Imageand brain: The resolution of the imagery debate. Cambridge, M.A.: MIT Press.

Kosslyn, S. M. (2005). Mental images and the brain. Cognitive Neuropsychology, 22(3/4), 333-347.

Kosslyn, S. M., \& Thompson, W. L. (2003). When is early visual cortex activated during visual mental imagery? Psychological Bulletin, 129, 723-746.

Kosslyn, S. M., \& Ochsner, K. (1994). Insearch of occipital activation during visual mental imagery. Trends in Neurosciences, 17, 290-292.

LeBihan, D., Turner, R., Zeffiro, T. A., Cuenod, C. A., Jezzard, P., \& Bonnerot, V. (1993). Activation of human primary visual cortex during mental imagery. In Functional MRI of the brain: A workshop presented by the Society of Magnetic Resonance in Medicine and the Society for Magnetic Resonance Imaging (pp.191-196). Arlington, V.A.: Society of Magnetic Resonance in Medicine, Inc..

Mandler, J., \& DeForest, M. (1977). The codeinthe node: Developmental differences in the use of a story schema. Discourse Processes, 1, 14-3.

Mandler, J. (1978). A code in the node: The use of a story schema in retrieval. Discourse Processes, 1(1), 14-22.

Mandler, J. (1984). Stories, scripts, and scenes:A spects of schema theory. Hillsdale, N.J.: Lawrence Erlbaum Associates.

Marshall, J. (2007). Imageas insight: Visual images in practice-based research. A Journal of Issues and Research, 49(1), 23-41.

McCoy, J., \& Evans, G. (2002). The potential role of the physical environment in fostering creativity. The Creativity Research Journal, 14(3\&4), 409-426.

Menon, R. S., Ogawa, S., Tank, D. W., Ellermann, J. M., Merkele, H., \& Ugurbil, K. (1993). Visual-mental imagery by functional brain MRI. In D. Le Bihan, R. Turner, M. Mosley, \& J. Hyde (Eds.), Functional MRI of the brain: A workshop presented by the society of magnetic resonance in medicine and the society for magnetic resonance imaging. Arlington, V.A.: Society of Magnetic Resonance in Medicine.

Miller, A. (2007). Unconscious thought, intuition, and visual imagery-A critique of "Working memory, cerebellum, and creativity". Creativity Research Journal, 19(1), 47-48.

Miyashita, Y. (1995). How the brain creates imagery: Projection to primary visual cortex. Science, New Series, 268(5218), $1719-1720$. 
Moscovitch, M., Wincour, G., \& Behrmann, M. (1997). What is special about face recognition? Ninteen experiments on a person with visual object agnosia and dyslexia but normal face recognition. Journal of Cognitive Neuroscience, 9, 555-604.

Mumford, M. D., \& Caughron, J. J. (2007). Neurology and creative thought: Some thoughts about working memory, the cerebellum, and creativity. Creativity Research Journal, 19, 49-54.

Nakakoji, K., Yamamoto, Y., \& Ohira, M. (1999). A framework that supports collective creativity in design using visual images: Appeared in creativity and cognition. In proceedings of the 3rd Conference on Creativity and Cognition (C\&C'99), Loughborough, UK, 1999.

Novick, L. R., \& Holyoak, K. J. (1991). Mathematical problem solving by analogy. Journal of Experimental Psychology: Learning, Memory and Cognition, 17, 398-415.

Pylyshyn, Z. W. (2002). Mental imagery: In search of a theory. Behavioral and Brain Sciences, 25, 157-238.

Pylyshyn, Z. W.(2003). Return of the mental image: Are there pictures in the brain? Trends in Cognitive Sciences, 7, 113-118.

Roland, P. E., \& Gulyas, B. (1994). Visual imagery and visual representation. Trendsin Neuroscience, 17, 281.

Sakai, K., \& Miyashita, Y. (1994). Visual imagery: An interaction between memory retrieval and focal attention. Trends in Neuroscience, 17, 287.

Shepard, R. N., \& Cooper, L. A. (1982). Mental images and their transformations. Cambridge, M.A.: MIT Press.

Siegler, R. S. (2006). Inter- and intra-individual differences in problem solving across the life span. In E. Bialystok \& F. I. M. Craik (Eds.), Life span cognition: Mechanisms of change (pp. 285-296). Oxford, U.K.: Oxford University Press.

Thomas, E., Place, N., \& Hillyard, C. (2008). Students and teachers to see: Using visual images in the college classroom to promote students' capabilities and skills. College Teaching, 56(1), 23-27.

Tuntoler, E., \& Resing, C. M. (2007). Effects of prior assistance inusing analogies on young children's unprompted analogical problem solving overtime: A Micro genetic study. British Journal of Educational Psychology, 77, 43-68.

Vandervert, R., Schimpf, H., \& Liu, H. (2003). How working memory and the cerebellum collaborate to produce creativity and innovation. Creativity Research Journal, 19(1), 1-18.

West, M. A. (1997). Developing creativityin organizations. Leicester, U.K.: British Psychological Society. 